\title{
Application of High Resolution Melt analysis (HRM) for screening haplotype variation in a non-model plant genus: Cyclopia (Honeybush)
}

\author{
Nicholas C Galuszynski ${ }^{\text {Corresp., }}{ }^{\text {, Alastair J Potts }}{ }^{1}$ \\ ${ }^{1}$ Department of Botany, Nelson Mandela University, Port Elizabeth, Eastern Cape, South Africa \\ Corresponding Author: Nicholas C Galuszynski \\ Email address: nicholas.galuszynski@gmail.com
}

Aim. This study has three broad aims: to a) develop genus-specific primers for High Resolution Melt analysis (HRM) of members of Cyclopia Vent., b) test the haplotype discrimination of HRM compared to Sanger sequencing, and c) provide an example of using HRM to detect novel haplotype variation in wild C. subternata Vogel. populations.

Location. The Cape Floristic Region (CFR), located along the southern Cape of South Africa.

Methods. Polymorphic loci were detected through a screening process of sequencing 12 non-coding chloroplast DNA segments across 14 Cyclopia species. Twelve genus-specific primer combinations were designed around variable cpDNA loci, four of which failed to amplify under PCR, the eight remaining were applied to test the specificity, sensitivity and accuracy of HRM. The three top performing HRM Primer combinations were then applied to detect novel haplotypes in wild $C$. subternata populations, and phylogeographic patterns of $C$. subternata were explored.

Results. We present a framework for applying HRM to non-model systems. HRM accuracy varied across the PCR products screened using the genus-specific primers developed, ranging between 56 and $100 \%$. The nucleotide variation failing to produce distinct melt curves is discussed. The top three performing regions, having $100 \%$ specificity (i.e. different haplotypes were never grouped into the same cluster, no false negatives), were able to detect novel haplotypes in wild $C$. subternata populations with high accuracy (96\%). Sensitivity below 100 \% (i.e. a single haplotype being clustered into multiple unique groups during HRM curve analysis, false positives) was resolved through sequence confirmation of each cluster resulting in a final accuracy of $100 \%$. Phylogeographic analyses revealed that wild $C$. subternata populations tend to exhibit phylogeographic structuring across mountain ranges (accounting for $73.8 \%$ of genetic variation base on an AMOVA), and genetic differentiation between populations increases with distance ( $p<0.05$ for IBD analyses).

Conclusions. After screening for regions with high HRM clustering specificity - akin to the screening process associated with most PCR based markers - the technology was found to be a high throughput tool for detecting genetic variation in non-model plants. 
1 Application of High Resolution Melt analysis (HRM) for 2 screening haplotype variation in a non-model plant

3 genus: Cyclopia (Honeybush)

4

5 Nicholas C. Galuszynski ${ }^{1}$, Alastair J. Potts ${ }^{1}$

6

7 Department of Botany, Nelson Mandela University, Port Elizabeth, Eastern

8 Cape, South Africa

10 Corresponding Author:

11 Nicholas C. Galuszynski ${ }^{1}$

12 University Way, Summerstrand, Port Elizabeth, 6011, South Africa

13 Email address: nicholas.galuszynski@gmail.com 


\section{Abstract}

15 Aim. This study has three broad aims: to a) develop genus-specific primers for High Resolution Melt analysis (HRM) of members of Cyclopia Vent., b) test the haplotype discrimination of HRM compared to Sanger sequencing, and c) provide an example of using HRM to detect novel haplotype variation in wild $C$. subternata Vogel. populations. Location. The Cape Floristic Region (CFR), located along the southern Cape of South Africa. Methods. Polymorphic loci were detected through a screening process of sequencing 12 noncoding chloroplast DNA segments across 14 Cyclopia species. Twelve genus-specific primer combinations were designed around variable cpDNA loci, four of which failed to amplify under PCR, the eight remaining were applied to test the specificity, sensitivity and accuracy of HRM. The three top performing HRM Primer combinations were then applied to detect novel haplotypes in wild $C$. subternata populations, and phylogeographic patterns of $C$. subternata were explored.

Results. We present a framework for applying HRM to non-model systems. HRM accuracy varied across the PCR products screened using the genus-specific primers developed, ranging between 56 and $100 \%$. The nucleotide variation failing to produce distinct melt curves is discussed. The top three performing regions, having $100 \%$ specificity (i.e. different haplotypes were never grouped into the same cluster, no false negatives), were able to detect novel haplotypes in wild C. subternata populations with high accuracy (96\%). Sensitivity below $100 \%$ (i.e. a single haplotype being clustered into multiple unique groups during HRM curve analysis, false positives) was resolved through sequence confirmation of each cluster resulting in a final accuracy of $100 \%$. Phylogeographic analyses revealed that wild C. subternata populations tend to exhibit phylogeographic structuring across mountain ranges (accounting for $73.8 \%$ of genetic variation base on an AMOVA), and genetic differentiation between populations increases with distance ( $p<0.05$ for IBD analyses).

Conclusions. After screening for regions with high HRM clustering specificity - akin to the screening process associated with most PCR based markers - the technology was found to be a high throughput tool for detecting genetic variation in non-model plants.

\section{Introduction}

Describing intra-population genetic diversity across a species range requires access to sufficiently variable genetic markers that can be applied to large sample sets in an efficient and cost effective manner. The lack of widely transferable marker systems with these qualities has impeded phylogeographic work in the past, especially in developing countries that harbour much of the planet's biodiversity (Beheregaray 2008). High Resolution Melt analysis (HRM, sometimes acronymed to HRMA) is a high throughput and cost effective means of screening sequence variation post Polymerase Chain Reaction (PCR), offering the unique advantage of providing rapid insights into the levels of sequence variation among samples through melt curve clustering. Having the flexibility to lend itself to a variety of applications, the technology has been widely adopted in clinical (reviewed by Vossen et al. 2009) and crop research (reviewed by Simko 2016). However, despite its apparent benefits, HRM appears to be underutilized for non-model organisms.

The HRM process is briefly described here. The inclusion of a DNA saturating fluorescent dye during PCR produces double stranded DNA molecules with dye bound to each base pair. As 
58

59

60

61

62

63

64

65

66

67

68

69

70

71

72

73

74

75

76

77

78

79

80

81

82

83

84

85

86

87

88

89

90

91

92

93

94

95

96

97

98

99

100

101

such, the presence of double stranded PCR product is measured by its fluorescence. As the PCR products are heated the double stranded DNA molecules dissociate, or melt, releasing the dye, resulting in a decrease in detected fluorescence. The rate at which a DNA fragment melts is dependent on the binding chemistry of the nucleotide sequence of the complementary strands under analysis. Therefore, by plotting the decrease in fluorescence against the steady rate of temperature increase, a melt curve determined by the DNA template under analysis is produced. The resultant melt curve differences (curve shape and melt peak [Tm]) are potentially indicative of sequence variation among PCR products.

The genotyping and mutation scanning abilities of HRM have been tested using well described systems in the past, including: artificially generated SNPs (Reed \& Wittwer 2004) and loci from the human genome (Ebili \& llyas 2015; Garritano et al. 2009; Li et al. 2014; Reed \& Wittwer 2004), where the technology was found to be highly sensitive and specific, with reproducible results. These studies suggest that HRM is capable of detecting single SNP variation with an average sensitivity of $95 \%$ ( $s d=8 \%$ ) and specificity of $97 \%(s d=7 \%)$ in amplicons of various lengths (50-1000 bp, Reed \& Wittwer 2004; 51-547 bp, Li et al. 2014; and 211-400 bp, Garritano et al. 2009). However, such accuracy is only possible if the starting DNA template is of sufficient quality and quantity (Ebili \& llyas 2015). Being non-destructive in nature, the PCR products can also be Sanger sequenced post HRM (Vossen et al. 2009). The power of the HRM approach to screen sequence variation is that it helps to avoid redundant sequencing of identical nucleotide motifs (Dang et al. 2012; Vossen et al. 2009), thereby potentially reducing overall sequencing costs of projects where intra-population genetic variation may be low, as in the slow evolving chloroplast genome of plants (Schaal et al. 1998). In addition, HRM has been shown to be more sensitive than traditional gel electrophoresis methods for microsatellite genotyping (Distefano et al. 2012). Fast, reliable and cost effective - HRM appears to be an ideal molecular tool for studies that require the characterization of a large number of samples that are likely to exhibit low nucleotide variation.

Despite its apparent utility, HRM has rarely featured in phylogeographic work. Smith et al. (2010) were some of the first to apply HRM to population genetics. By melting short amplicons (40-60 bp) that targeted known SNPs, they successfully genotyped 121 accessions from five wild swordfish (Xiphias gladius Bloch, Xiphiidae) populations. Cubry et al. (2015) were successful in applying HRM for the discrimination of four cpDNA haplotypes that corresponded with the geographic structuring of black alder (Alnus glutinosa (L.) Gaertn., Betulaceae), screening 154 accessions across 23 populations. These studies, and most others applying HRM to non-model organisms (Dang et al. 2012; Li et al. 2012; Radvansky et al. 2011), set out to develop HRM primers having prior knowledge of the nucleotide variation under analyses.

Unfortunately, such knowledge is generally not available for the study of non-model organisms and the application of HRM for detecting and genotyping of novel genetic variation in wild populations is still rare (Nunziata et al. 2019; Sillo et al. 2017). High Resolution Melt analysis appears to be an underutilized resource by phylogeographers. Here we test the application of HRM for non-model taxa, Cyclopia, a commercially important plant genus endemic to the CFR. This study: a) develops a set of genus-specific primers for the HRM analysis of non-coding cpDNA loci to test: b) the haplotype discrimination sensitivity, specificity, and accuracy of HRM, and c) the potential application of HRM for haplotype detection in wild Cyclopia populations, focusing here on C. subternata. This study demonstrates 
102 that (when optimized) HRM is a fast, accurate, and cost effective tool for haplotype detection in 103 non-model organisms, successfully describing the geographic structuring of genetic diversity in 104 wild C. subternata populations.

105

106

107

108

109

110

111

112

113

114

115

116

117

118

119

120

121

122

123

124

125

126

127

128

129

130

131

132

133

134

135

136

137

138

139

140

141

142

\section{Materials \& Methods}

\section{Taxonomic background and sampling}

This study focuses on members of the genus Cyclopia Vent., which is endemic to the Cape Floristic Region (CFR) and consists of 23 described species; two of which are considered extinct (Cyclopia filiformis Kies, Cyclopia laxiflora Benth.) and various others ranging from critically endangered to vulnerable (SANBI, 2012). Cyclopia species and populations tend to exhibit highly localised distributions (Schutte 1997), making them potentially vulnerable to genetic pollution from foreign genotypes translocated for the cultivation of Honeybush tea and associated products (Ellstrand \& Elam 1993; Levin et al. 1996; Potts 2017; Schutte 1997) - an increasingly common practice in the CFR (McGregor 2017). The characterization and conservation of wild Cyclopia genetic diversity is therefore of high importance.

To maximise the amount of genetic variation detected and the transferability of the primers designed across the genus, 14 species (summarized in Table 1, closed circles in Fig 1) were sampled from the full geographic range of the genus. Additionally, eight wild populations (open circles in Fig 1) of $C$. subternata Vogel. were sampled to test the potential application of HRM for haplotype detection using the genus-specific primers generated. Between 10 and 24 samples were collected per $C$. subternata population. Fresh leaf material was clipped from the growing tips of wild specimens over the period of 2015-2018 and placed directly into a silica desiccating medium for a minimum of two weeks prior to DNA extraction. All sampling was approved by the relevant permitting agencies, Cape Nature (Permit number: CN35-28-4367), the Eastern Cape Department of Economic Development, Environmental Affairs and Tourism (Permit numbers: CRO 84/ 16CR, CRO 85/ 16CR), and the Eastern Cape Parks and Tourism Agency (Permit number: RA_0185).

\section{DNA extraction}

Whole genomic DNA was extracted from silica-dried leaf material using a CTAB approach modified from Doyle and Doyle (1987), the full extraction protocol is described in Methods S1. Extracted DNA was suspended in $50 \mu \mathrm{L}$ molecular grade water for PCR amplification with the products sequenced using Sanger sequencing (Sanger et al. 1977). Samples that failed to amplify during PCR, were subject to repeat DNA extracted from new leaf material and then PCR amplified.

\section{Developing Cyclopia specific HRM primers}

While HRM has been shown to successfully detect sequence variation in PCR products of various sizes (see introduction), it has been suggested that shorter PCR products are likely to produce more pronounced melt curve differences than larger products with the same nucleotide variation (Dang et al. 2012; Dobrowolski et al. 2009; Li et al. 2014; Liew et al. 2004; Smith et al. 2013; Taylor et al. 2011). Universal marker systems, such as those developed by Shaw et al. $(2005,2007)$ are therefore unlikely to be directly transferable to HRM, as they amplify relatively 
143 large PCR products, thus HRM specific primers must be developed to target shorter, variable 144 regions.

145 Developing HRM primers requires prior knowledge of the nucleotide variation of regions across

146 samples. The means of acquiring such data is dependent on the resources available to the

147 researcher and the availability of existing sequence data for the study organisms. Thus template

148 data could range from Next Generation Sequencing derived genomic data to the application of

149 HRM to existing microsatellite markers, or existing data available from international nucleotide

150 sequence databases such as GenBank (https://www.ncbi.nlm.nih.gov/genbank/).

151 For Cyclopia, however, existing sequence data (predominantly from the ribosomal ITS region)

152 exhibited low levels of differentiation amongst species (Galuszynski and Potts 2017; Van Der

153 Bank et al. 2002), lacking the variation required for population level analyses. Therefore,

154 polymorphic loci were identified from non-coding cpDNA regions via Sanger sequencing

155 (Sanger et al. 1977) of PCR products amplified using the protocols and universal primers

156 described by Shaw et al. $(2005,2007)$. A total of 16 non-coding cpDNA regions under went

157 PCR, however four regions failed to amplify (and could not be sequenced). The 12 regions that

158 were sequenced are summarized in Table 1, all necleotide sequence data is availible from

159 GenBank and accession numbers are provided in Table S1.

160 Sequences were assembled using CondonCode Aligner [v2.0.1] (Codon Code Corp, http://www.

161 codoncode.com). The PHRED base-calling program (Ewing et al. 1998) was used to assign a

162 quality score for each sequence, then sequences were automatically aligned using ClustalW

163 (Thompson et al. 1994) and visually inspected for quality. All short indels (<3 bp) occurring in

164 homopolymer repeat regions were considered alignment errors and removed from the

165 alignment. The consensus sequence alignment for polymorphic regions were exported and

166 utilized in HRM primer design.

167 Primer design was guided by two constraining factors: (1) sequences had to contain

168 conservative regions with a high GC content that could form the primer binding template, and

169 (2) these regions had to flank polymorphic sites. Wherever possible, internal HRM primers were

170 designed in a way that would split a region into neighboring loci, as suggested by Dang et al.

171 (2012). This approach allows for adjacent loci to be sequenced in a single run by amplifying the

172 full region, and then during alignment, split the region into the neighboring loci that underwent

173 HRM analysis. This approach reduces the time involved in sequence alignment and number of

174 samples required to be sequenced for HRM clustering verification.

175 High Resolution Melt specific primers were designed using the online resource Primer-Blast

176 (www.ncbi.nlm.nih.gov/tools/primer-blast/). The sub-family Faboideae was used as the

177 reference taxon to check for primer specificity searched against the NCBI Reference Sequence

178 representative genomes (www.ncbi.nlm.nih.gov/refseq/); PCR product size was limited to

179 between 50 and $550 \mathrm{bp}$ (as this falls within the amplicon size predicted to produce the highest

180 levels of genotyping accuracy; Dang et al. 2012; Dobrowolski et al. 2009; Li et al. 2014; Liew et

181 al. 2004; Taylor et al. 2011), primer melting temperature was set at $60^{\circ} \mathrm{C}\left( \pm 3^{\circ} \mathrm{C}\right)$ (as

182 suggested by Taylor et al. 2011) and a maximum of 20 primer pairs were returned per search.

183 The positions of these primers within their respective region alignment were manually evaluated

184 to ensure that they occurred in well conserved sites, i.e. any primers occurring across

185 polymorphic loci were discarded. 
186 Eleven genus-specific primer pairs (Table S2) were developed from seven of the twelve non-

187

188

189

190

191

192

193

194

195

196

197

198

199

200

201

202

203

204

205

206

207

208

209

210

211

212

213

214

215

216

217

218

219

220

221

222

223

224

225

226

227 coding cpDNA regions, of which eight primer pairs successfully amplified PCR products and were thus selected for HRM screening (Table 2). The remaining three were excluded from the analysis due to poor PCR amplification. The primer pairs selected for HRM screening amplified between four and six unique haplotypes each, across five cpDNA regions (nucleotide differences are summarized in Table 3). Primers selected for the evaluation of HRM accuracy are reported in Table 2.

\section{Testing PCR amplification of HRM primers}

The genomic DNA extracted for samples that amplified unique haplotypes (as determined from the sequence data used to develop HRM primers) was quantified using a NanoDrop 2000c spectrophotometer (Thermo Fisher Scientific, Wilmington, DE19810r Scientific, USA) and $5 \mathrm{ng} / \mathrm{L}$ DNA dilutions were made for HRM analysis. High Resolution Melt analysis was conducted for all primer pairs developed, with 16 replicates amplified per sample (haplotype). However, only replicates that produced sufficient PCR products, as determined from PCR amplification curves (see examples in Fig 2 and 3 ) were included in the evaluation of HRM haplotype discrimination (number of replicated subjected to HRM analysis for each haplotype are reported in Table 3). This PCR amplification screening approach was adopted as the aim of this phase of the study was to test the haplotype discrimination abilities of HRM based on the underlying nucleotide differences between haplotypes and not the quantity and quality of PCR product under analysis (which can vary due to pippetting errors). Regions that failed to produce consistent PCR amplification curves (possibly due to non-specific primer binding), were excluded from subsequent analysis (see examples of PCR and HRM curves excluded from analysis in Figs 2 and 3).

\section{PCR and HRM reactions}

All reactions (PCR amplification and subsequent HRM) took place in a 96 well plate CFX Connect (Bio-Rad Laboratories, Hercules, California, U.S.A.) in $10 \mu \mathrm{L}$ reaction setups, consisting of $4 \mu \mathrm{L}$ genomic DNA ( $5 \mathrm{ng} / \mu \mathrm{L}), 1 \mu \mathrm{L}$ each primer $(10 \mathrm{mM})$ and $5 \mu \mathrm{L}$ Precision Melt Supermix containing hot-start iTaqTM DNA polymerase, dNTPs, MgCl2, EvaGreen dye (BioRad Laboratories, Hercules, California, U.S.A.).

Polymerase Chain Reaction amplification and melt conditions were as per manufacturer's specifications (Table 4) and the annealing temperature set to the primer pair's mean Tm (melting temperature), reported in Table 2. The automated clustering algorithm of the High Precision Melt software ${ }^{\mathrm{TM}}$ (Bio-Rad Laboratories, Hercules, California, U.S.A.) was performed on the normalized florescence data and used to group melt curves into clusters that represent putative haplotypes. HRM clustering settings used were $\Delta \mathrm{Tm}$ threshold at $0.05{ }^{\circ} \mathrm{C}$ and curve shape sensitivity settings and temperature correction, $70 \%$ and 20 respectively.

\section{HRM discrimination of sequenced haplotypes}

Following the descriptions of Altman and Bland (1994), HRM discrimination (sensitivity, specificity and accuracy) was determined for each of the haplotypes amplified by the eight HRM primers that produced sufficient PCR product for HRM analysis. Sensitivity, or the true positive rate, refers to HRM's ability to correctly assign haplotype replicates into the same HRM cluster.

Sensitivity $=T P /(T P+F N)$ 
228

229

230

231

232

233

234

235

236

237

238

239

240

241

242

243

244

245

246

247

248

249

250

251

252

253

254

255

256

257

258

259

260

261

262

263

264

265

266

267

268

$\mathrm{TP}=$ TruePositive $\mathrm{FN}=$ FalseNegative

Specificity, or true negative rate, is the measure of HRM's ability to correctly discern between haplotypes, grouping them into different HRM clusters.

$$
\text { Specificity }=\mathrm{TN} /(\mathrm{TN}+\mathrm{FP})
$$

$\mathrm{TN}=$ TrueNegative $\mathrm{FP}=$ FalsePositive

The accuracy of HRM refers to how close haplotype clustering reflects the true identities of the haplotypes and was measured as:

$$
\text { Accuracy }=(T P+T N) /(T P+F P+T N+F N)
$$

Since sensitivity below $100 \%$ will be accounted for during HRM cluster (i.e. putative haplotype) confirmation by sequencing (with a subset of samples from each unique HRM cluster sequenced), all regions with $100 \%$ specificity were included for the detection of novel haplotypes in wild $C$. subternata populations.

\section{The potential for HRM to detect haplotype variation in wild populations}

Only three regions (MLT S1 - MLT S2, MLT S3 - MLT S4, and MLT U1 - MLT U2) were found to have an HRM clustering specificity of $100 \%$ (Fig 4). Thus these regions were screened for haplotype variation across 142 accessions from eight wild $C$. subternata populations.

The same approach as Dang et al. (2012) was employed, with each sample run in duplicate and haplotype clustering performed on a single population basis with the intention of reducing errors resulting from variation of PCR product concentration and quality across samples from different population extractions. This was achieved by using the built in well group function in the CFX Manager ${ }^{\mathrm{TM}}$ Software (Bio-Rad Laboratories, Hercules, California, U.S.A.), thus multiple populations could be included in a run, but analyses separately for HRM clustering. The cpDNA regions that were used to design the primers used for HRM haplotype detection were amplified and sequenced (following the same protocols as before) to confirm the haplotype identity of HRM clusters. The loci amplified by MLT S1- MLT S2 and MLT S3 - MLT S4 are adjacent to one another and by sequencing the full atpl-atpH intergenic spacer, the sequence identity of both loci could be confirmed with reduced sequencing and alignment effort. Moreover, the position of the loci amplified by the HRM primers occurred near the center of their respective parent regions and unidirectional sequencing using the reverse primers of Shaw et al. (2007) proved sufficient for verifying the sequence motifs under HRM analysis. A minimum of three accessions representing each HRM cluster (i.e. putative haplotype) in each population were sequenced for haplotype verification. Samples whose replicates were classified as two different clusters, thus having uncertain haplotype identity, were also sequenced to ensure they were assigned correctly. A total of 46 and 38 accessions were sequenced for the atpl-atpH intergenic spacer and $n d h A$ intron, respectively. Haplotype discrimination by HRM was calculated using the $C$. subternata samples sequenced for haplotype confirmation, following the same formula as before.

\section{Phylogeographic analysis of C. subternata}

The haplotypes detected via HRM clustering and confirmed by sequencing (described above) were assembled following the same procedure described under 'Developing Cyclopia specific HRM primers'. All wild $C$. subternata samples that underwent HRM analysis were then assigned 
269 the haplotype identity of the HRM cluster they belonged using a custom $R$ script written by A.J.P

270

271

272

273

274

275

276

277

278

279

280

281

282

283

284

285

286

287

288

289

290

291

292

293

294

295

296

297

298

299

300

301

302

303

304

305

306

307

308

309

310

311 (provided as File S1 which includes example files for running the script). The cpDNA regions under investigation (atpl-atpH intergenic spacer and $n d h A$ intron) are maternally inherited in tandem and not subject to recombination (Reboud and Zeyl, 1994), and were therefore concatenated for subsequent analysis.

The genealogical relationships among the concatenated haplotypes were determined from a Statistical Parsimony (SP) network (Fig 5 inset) constructed in TCS [V1.2.1] (Clement et al. 2000). Two $C$. intermedia E. Mey. individuals with existing sequence data for the atpl-atpH intergenic spacer and $n d h A$ intron generated during the primer development phase of the study were included as outgroup taxa. Default options were used to build the network and all indels were reduced to single base-pairs as the software treats a multiple base pair gap as multiple mutations. Haplotype distributions were mapped (Fig 5) in QGIS [V3.2.2] (QGIS Development Team 2018).

The following population genetic differentiation measures were calculated from the concatenated haplotypes: pairwise Gst (Nei 1973), G"'st (Hedrick 2005) (both indicators of allele fixation) Jost's D (Jost 2008), which measures allelic differentiation between populations, and Prevosi's dist (Prevosti et al. 1975) a measure of pairwise population genetic distance that counts gaps as evolutionary events (all gaps were reduced to single base pair events). These measures provide insight into current allele distributions without assuming historical gene flow patterns (Jost et al. 2018). Isolation By Distance (IBD) was evaluated among populations testing the correlation between these genetic differentiation measures and pairwise geographic distance using a Mantel test (Wright 1943) with 9999 permutations, as implemented using the ade4 [v1.7] library (Dray \& Dufour 2007; Kamvar et al. 2014) in R [v3.5.1] (R Core Team 2018). In order to account for the possibility of non linear population expansion, relationship between population differentiation measures and the natural logarithm of geographic distance was tested following the same approach (Rousset, 1997). Finally, genetic differentiation across the mountain ranges that populations were sampled from was tested via an Analysis of Molecular Variance (AMOVA) (Excoffier et al. 1992). The mountain ranges included in the AMOVA included: the Tsitsikamma (3 populations, 52 samples), Outeniqua east (2 populations, 31 samples), Outeniqua west (2 populations, 35 samples), and Langeberg (1 population, 24 samples) ranges, as described in Table 5.

\section{Results}

\section{HRM discrimination of sequenced haplotypes}

High Resolution Melt curve clustering of haplotypes identified via sequencing for primer development produced variable results: sensitivity ranged from $56 \%$ - $100 \%$, specificity ranged from $27 \%-100 \%$, and accuracy ranged from $36 \%-100 \%$ (the number of replicates assigned to each HRM cluster is reported in Table 3 and sensitivity, specificity and accuracy is summarized in Fig 4).

Nucleotide differences between haplotypes failing to produce distinct melt curves, and thus undifferentiated by HRM clustering, are summarized in Table 6. Of the haplotypes not differentiated by HRM: two haplotypes differ by indels, while the remaining 15 comparisons differ by at least one transversion, and two comparisons differed by a transversion and transition. The haplotypes that did produce distinct melt curves differed by at least a transition 
312 (26 cases), or multiple SNPs (16 cases), one haplotype differed by a 19 bp indel, and another

313 by a 6 bp indel. All haplotype sequence variation is summarized in Table 3. As previously

314 stated, the three HRM primer combinations with specificity of $100 \%$, two targeting the atpl-atpH

315 intergenic spacer (MLT S1 -S2, MLT S3 - MLT S4) and one targetting ndhA intron (MLT U1 -

316 U2), were selected for haplotype discovery in wild C. subternata populations.

317 Detection of haplotype variation in wild populations via HRM

318 High Resolution Melt curve analysis of accessions from wild C. subternata populations revealed

319 no variation in the cpDNA haplotypes amplified by the MLT S3 - MLT S4 primer combination,

320 confirmed by sequencing, and the locus was subsequently excluded from further analyses. Five

321

322 distinct haplotypes were verified by sequencing a subset of samples (ranging from three to eight individuals per population) from each HRM cluster for the remaining two primer combinations.

323 Of the 142 samples less than $29 \%$ were required to be sequenced for haplotype confirmation.

324

325 Both loci were found to have $100 \%$ specificity, i.e. HRM successfully discriminated among all haplotypes detected in wild $C$. subternata populations. However, haplotype richness was overestimated by HRM (sensitivity of $87.6 \%$ and $95.5 \%$ for MLT S1 - MLT S2 and MLT U1 -

326

327

328

329 MLT U2 respectively), both cpDNA regions had accuracies of $96 \%$. However, as these additional clusters were sequenced for haplotype confirmation, samples were assigned the true identity of haplotypes resolving any potential issues of low sensitivity.

330

331 The final cpDNA dataset comprised $561 \mathrm{bp}, 217 \mathrm{bp}$ from the atp/-atpH intergenic spacer (MLT S1 - MLT S2) and $344 \mathrm{bp}$ from the ndhA intron (MLT U1 - MLT U2), with a GC content of $29 \%$. An additional 310 base pairs (bp) were amplified by MLT S3 - MLT S4, revealing no nucleotide

333

334 variation. The dataset contained five polymorphic sites; four transversions, one transition, and a seven bp indel (nucleotide differences summarised in Table S3).

The SP network revealed a radiation from a central ancestral haplotype, with few mutations separating haplotypes (Fig 5 inset). The ancestral haplotype was present in all populations, except the western most Garcia's Pass population, located in the Langberg Mountains. This population contains a single, unique haplotype. An additional two populations (Kareedouw Pass and Bloukrans Bridge) were also found to contain rare, localized haplotypes and a low frequency haplotype was detected in two populations located in the Tsitsikamma and Outeniqua mountains (Fig 5). Population genetic differentiation measures increased with geographic distance $\left(\mathrm{R}^{\wedge} 2=0.77,0.74,0.70\right.$, and 0.76 for Gst, G"st, Jost's $\mathrm{D}$ and Provesti's dist respectively, $p<0.05$ for all measures), with significance increasing when tested against log transformed geographic distance $\left(\mathrm{R}^{\wedge} 2=0.64,0.67,0.61\right.$, and 0.65 for Gst, G"st, Jost's $\mathrm{D}$ and Provesti's dist as before, $p<0.05$ for all measures). The AMOVA revealed significant $(p<0.05)$ structuring across mountain ranges, accounting for $73.8 \%$ of genetic variation (AMOVA results summarised in Table S4).

\section{Discussion}

350 A nested framework (Fig 3) was developed to test and apply HRM to non-model organisms, members of the Cape endemic plant genus Cyclopia. Polymorphic sites were identified via sequencing 12 non-coding cpDNA regions across 14 Cyclopia species. PCR primers for HRM 
353

354

355

356

357

358

359

360

361

362

363

364

365

366

367

368

369

370

371

372

373

374

375

376

377

378

379

380

381

382

383

384

385

386

387

388

389

390

391

392

393

394

395

analysis were designed to flank these variable sites, producing 11 HRM primer pairs across 7 regions. Eight of these pairs successfully amplified PCR products and were subsequently analysed via HRM. Specificity of $100 \%$ was detected for three of the primer pairs, which were then used to detect haplotype variation in wild $C$. subternata populations with a haplotypes detection accuracy of $96 \%$. Haplotype detection errors were due to false negatives reducing HRM sensitivity. False negatives occur when HRM incorrectly assigns a single haplotype to multiple clustering groups, an issue that is resolved when the haplotype identity of HRM clusters is confirmed by sequencing. Optimized HRM was demonstrated to be a powerful tool for detecting genetic variation in non-model organisms, providing immediate insights into within population genetic variation via automated melt curve clustering and substantially reduced sequencing efforts. The framework provided here offers a straightforward approach to develop and test the potential application of HRM to non-model systems.

\section{HRM discrimination of sequenced haplotypes}

Differences in DNA melt curves, as detected by HRM, stem from the effects nucleotide sequence chemistry has on melt peak intensity and curve shape. While HRM is reported to be capable of discriminating between any SNP type, the approach may be constrained by physical and chemical properties of the DNA fragment under melt analysis (Gundry et al. 2008). Some nucleotide variations, namely class $3(C \leftrightarrow G)$ and class $4(A \leftrightarrow T)$ SNPS, tend to produce negligible changes in melt behaviour (curve shape and melt peak) and are often poorly detected by HRM (Dang et al. 2012; Gundry et al. 2008; Yamagata et al. 2018). This is likely to be exaggerated when analysing longer PCR products, as shorter PCR products produce more pronounced melt curve differences than longer nucleotide motifs with the same SNP variation (Li et al. 2014; Liew et al. 2004; Taylor et al. 2011; Tindall et al. 2009). Furthermore, nearest neighbour chemistry (the identity of nucleotides directly adjacent to the SNP under investigation) has been shown to impact the melt peak of PCR products, negating any change in melt peak produced by class 3 and 4 SNPs in some cases (Yamagata et al. 2018).

Many of these observations are supported by the findings of this study, however some important deviations were detected. Haplotypes that were successfully discriminated by HRM tended to have a class 1 SNP (transitions, $C \leftrightarrow T$ and $A \leftrightarrow G$ ) or multiple SNPs differentiating them. However, seven haplotypes differing by multiple SNPs did not produce distinct melt curves (Table 6), suggesting that some SNPs may potentially counteract one anothers impact on the melt curve. Furthermore, haplotypes that differed by a class 2 (transversions, $C \leftrightarrow A, G \leftrightarrow T$ ) and, as predicted, class 4 SNPs do not appear to have detectable melt curve differences. It is, however, uncertain why in this study some class 2 SNPs produced distinct melt curves in some cases (MLT M1 - MLT M2 and MLT S3 - MLT S4), but not in others (MLT C1-C4 and MLT C3 C4). Nearest neighbor chemistry does not appear to be provide insights into this as the SNPs had the same neighbouring base pairs across PCR products. Furthermore, a class 2 SNP was differentiated by HRM in a larger PCR product ( $527 \mathrm{bp}$ ) and not in the smaller products (386 bp and $236 \mathrm{bp}$ ), indicating that shorter DNA fragments do not necessarily produce more distinct melt curves than larger fragments with the same nucleotide differences.

The primer design choices in this study were largely based on the suggestions that nucleotide variation in shorter DNA strands will have a more pronounced impact on melt curve shape and intensity. This appears to have not been the case and larger PCR products performed as well, if 
396

397

398

399

400

401

402

403

404

405

406

407

408

409

410

411

412

413

414

415

416

417

418

419

420

421

422

423

424

425

426

427

428

429

430

431

432

433

434

435

436

437

438

not better, than smaller regions, as detected elsewhere (Dang et al. 2012; Dobrowolski et al. 2009). Future HRM primer design efforts should possibly explore larger target regions that are more likely to cover multiple SNPs and thus produce more distinct melt curves (Dang et al. 2012), such as the products amplified by primer combinations; MLT S1- MLT S2, MLT S3 - MLT S4, and MLT U1- MLT U2. This opens HRM up to exploration of existing universal primers, such as those of Shaw et al. $(2005,2007)$, but additional PCR optimization may be required prior to being applied to HRM.

\section{Detection of haplotype variation in wild Cyclopia populations via HRM} High Resolution Melt analysis using the two best performing primer pairs that amplified variable regions proved to be a highly accurate ( $96 \%$ for both regions screened) means of detecting haplotypes variation in wild Cyclopia populations with no cases of different haplotypes occurring in the same cluster (specificity $=100 \%$ ).

A remarkable feature of HRM is its high and rapid throughput. Running samples in duplicate on a 96 well plate allowed for 48 samples to be screened every three hours. As such, all 142 wild C. subternata samples were screened across the two cpDNA regions in two days, with immediate insights into the underlying levels of genetic variation (based on HRM clusterings). This rapid data production comes at a minimal cost per sample, which in this study amounted to \$11.09 including all PCR amplification and sequencing for the phylogeographic analysis of $C$. subternata. A costing analysis based on quotes obtained in 2017, for a broader Cyclopia research project that employed Anchored Hybrid Enrichment (Lemmon et al. 2012) for nucleotide sequence generation, revealed that, while the cost per bp was not greatly reduced when applying HRM (\$0.013/bp) as compared to Sanger sequencing (\$0.015/bp), and more costly than high throughput sequencing approaches $(\$ 0.0005 / \mathrm{bp}$, excluding library preparation and bioinformatic services). The true value of HRM lies in the ability to screen large numbers of samples, with the cost per sample for HRM being $40 \%$ that of Sanger sequencing and $16 \%$ that of Anchored Hybrid Enrichment.

\section{Distribution of C. subternata genetic diversity}

Despite the relatively low genetic differentiation and variation detected across wild $C$. subternata populations, with a widespread haplotype detected in all populations sampled in the

Tsitsikamma and Outeniqua mountains, genetic diversity does appear to be spatially structured. Geographically isolated haplotypes were detected in populations in the Tsitsikamma mountains, and complete haplotype turnover was detected in Garcia's Pass population from the Langeberg; possibly a consequence of a genetic bottleneck resulting from a small founding population, facilitating rapid fixation of rare alleles (Klopfstein et al. 2006). These, and an additional low frequency haplotype shared between Langkloof and Outeniqua populations, provided sufficient divergence across mountain ranges to be detected by an AMOVA and roughly coincide with NJ clustering of populations (Fig S1). The transition between mountain ranges represents steps of increased genetic differentiation between populations (supported by significant IBD, Slatkin 1993), and the movement of seed and seedlings across these isolating barriers for Honeybush cultivation should be avoided.

The population divergence described above is in contrast to that reported for the nuclear genome of C. subternata (Niemandt et al. 2018). While Niemand et al. (2018) also detected a genetically unique population (located in Harlem), no C. subternata was detected in this area 
439

440

441

442

443

444

445

446

447

448

449

450

451

452

453

454

455

456

457

458

459

460

461

462

463

464

465

466

467

468

469

470

471

472

473

474

475

476

477

478

479

480

481

482

during sampling activities despite assistance from landowners in locating wild C. plicata Kies populations (iNaturalist observation 14257580) that have been harvested and traded as $C$. subternata. We suggested that additional work be done to describe the C. plicata and $C$. subternata populations in this area to confirm potential sympatry between these two morphologically and ecologically similar species (Schutte, 1997). No genetic divergence was reported between the two wild $C$. subternata populations (sampled from the Tsitsikamma and Outeniqua mountains) screened and the Agricultural Research Council's (ARC) genebank accessions (Niemandt et al. 2018). Genetic material from this genebank has recently been made commercially available for the establishment of cultivated Honeybush stands, including in the Langeberg that supports the genetically distinct GAR population (Joubert et al. 2011; Niemandt et al. 2018). The effective population size of the $C$. subternata nuclear genome is a scale of magnitude larger than the cpDNA due to the species high ploidy level (hexalpoid, $2 \mathrm{n}=$ $6 x=54$, Motsa et al. 2018; Schutte 1997), as such drift may occur more slowly. Additionally, pollen dispersal by carpenter bees (Xylocopa spp) may reduce population divergence through rare long distance dispersal events. Seed, in contrast, is dispersed locally by ants (Schutte 1997) and dehiscent seed pods and long distance dispersal is extremely unlikely, unless anthropogenically mediated; this has likely been the case with genetic material actively redistributed across the CFR for the establishment of cultivated populations and breeding trials(Joubert et al. 2011).

The geographic distribution of $C$. subternata genetic diversity, as described here, indicates that: a) unique haplotypes occur within populations, and b) these unique haplotypes are spatially structured. These patterns of genetic diversity need to be acknowledged in the management of this economically important species, with seed and seedling not translocated outside of the mountain range that they were sourced from.

\section{Conclusions}

This study demonstrates that HRM is capable of discerning between cpDNA haplotypes, with variable levels of success. When the top performing HRM regions were applied to screening genetic variation in wild populations of the non-model organism, C. subternata, all haplotypes were differentiated. While the framework described herein provides a clear guideline on generating the markers required for applying HRM to non-model systems, some analytical adjustments may be required based on the HRM platform available to the lab in question. The high throughput of HRM offers the molecular ecologist the opportunity to increase intrapopulation sample numbers without increasing project costs, while the automated clustering provides real time insights into the underlying levels of genetic variation. Furthermore, this technology may be particularly well suited to the study of conserved and slow mutating nuclear regions and the chloroplast genome of plants (Schaal et al. 1998) where low intrapopulation genetic variation is predicted and redundant sequencing of the same nucleotide motifs is likely. The Cyclopia specific primers developed here provide a starting point for assessing potential issues of genetic pollution associated with the transition to commercial Honeybush cultivation (Potts 2017). However, further resolution may be required for more in depth population studies and additional cpDNA regions as well as low copy nuclear loci should be explored for HRM primer development. Furthermore, the tools produced here, while suitable for phylogeographic work (as demonstrated here), are limited to the maternally inherited chloroplast genome and are not suitable for exploration of interspecific hybrid detection in cultivated Honeybush populations.

PeerJ reviewing PDF | (2019:12:43978:2:0:NEW 18 Apr 2020) 


\section{Acknowledgements}

We would like to thank Gillian McGregor and her students, Nicola van Berkel, Dianne Turner, as well as the Agricultural Research Council of South Africa for their assistance in sample collection and for the valuable discussions on Honeybush ecology and industry. We would also like to thank A. Shutte-Vlock for providing us with samples of hard to collect species and for always being willing to assist in identifying species. We thank the agencies that provided the funding for this research, the National Research Fund of South Africa (Grant No. 99034, 95992, 114687) and the Table Mountain Fund (Grant no. TM2499) and the various land-owners and conservation bodies that allowed for sample collection. Additionally, we acknowledge Dr J. R. Alvarado-Bremer and one anonymous reviewer for their comments that improved the quality and clarity of this manuscript.

\section{References}

Altman, D. G., \& Bland, J. M. (1994). Diagnostic tests. 1: Sensitivity and specificity. BMJ (Clinical research ed.), 308(6943), 1552.

Beheregaray, L. B. (2008). Twenty years of phylogeography: The state of the field and the challenges for the Southern Hemisphere. Mol. Ecol., 17(17), 3754-3774.

Clement, M., Posada, D., \& Crandall, K. A. (2000). TCS: A computer program to estimate gene genealogies. Mol. Ecol., 9(10), 1657-1659.

Cubry, P., Gallagher, E., O'Connor, E., \& Kelleher, C. T. (2015). Phylogeography and population genetics of black alder (Alnus glutinosa (L.) Gaertn.) in Ireland: putting it in a European context. Tree Genet. Genomes, 11(5), 99.

Dang, X. D., Kelleher, C. T., Howard-Williams, E., \& Meade, C. V. (2012). Rapid identification of chloroplast haplotypes using High Resolution Melting analysis. Mol. Ecol. Resour., 12(5), 894908.

Distefano, G., Caruso, M., La Malfa, S., Gentile, A., \& Wu, S.-B. (2012). High resolution melting analysis is a more sensitive and effective alternative to gel-based platforms in analysis of SSR: An example in citrus. PLoS One, 7(8), e44202.

Dobrowolski, S. F., Hendricks, A. T. M., van den Bosch, B. J. C., Smeets, H. J. M., Gray, J., Miller, T., \& Sears, M. (2009). Identifying sequence variants in the human mitochondrial genome using high-resolution melt (HRM) profiling. Hum. Mutat., 30(6), 891-898.

Doyle, J. J., \& Doyle, J. L. (1987). A rapid DNA isolation procedure for small quantities of fresh leaf tissue. Phytochem. Bull., 19, 11-15.

Dray, S., \& Dufour, A.-B. (2007). The ade4 Package: Implementing the duality diagram for ecologists. J. Stat. Softw., 22(4).

Ebili, H., \& llyas, M. (2015). High resolution melt analysis, DNA template quantity disparities and result reliability. Clin. Lab., 61(1-2), 155-159.

Ellstrand, N. C., \& Elam, D. R. (1993). Population genetic consequences of small population size: Implications for plant conservation. Annu. Rev. Ecol. Evol. Syst., 24(1), 217-242.

Ewing, B., Hillier, L., Wendl, M. C., \& Green, P. (1998). Base-calling of automated sequencer traces using phred. I. Accuracy assessment. Genome Res., 8(3), 175-185.

Excoffier, L., Smouse, P. E., \& Quattro, J. M. (1992). Analysis of molecular variance inferred from metric distances among DNA haplotypes: Application to human mitochondrial DNA restriction data. Genetics, 131(2), 479-491. 
528 Galuszynski, N. C., \& Potts, A. J. (2017). Barcoding life in the Cape: insights from the

529 phylogeography of a small Cape genus. Genome, 60 (11), 935-936.

530 Garritano, S., Gemignani, F., Voegele, C., Nguyen-Dumont, T., Le Calvez-Kelm, F., De Silva D.,

531 Lesueur F., Landi S., \& Tavtigian S.V. (2009). Determining the effectiveness of High Resolution

532 Melting analysis for SNP genotyping and mutation scanning at the TP53 locus. BMC Genet., 10,

5335.

534 Gundry, C. N., Dobrowolski, S. F., Martin, Y. R., Robbins, T. C., Nay, L. M., Boyd, N., \& Teng,

535 D. H. F. (2008). Base-pair neutral homozygotes can be discriminated by calibrated high-

536 resolution melting of small amplicons. Nucleic Acids Res., 36(10), 3401-3408.

537 Hedrick, P. W. (2005). A standardized genetic differentiation measure. Evolution, 59(8), 1633-

5381638.

539 Jost, L. (2008). GST and its relatives do not measure differentiation. Mol. Ecol., 17(18), 4015-

5404026.

541 Jost, L., Archer, F., Flanagan, S., Gaggiotti, O., Hoban, S., \& Latch, E. (2018). Differentiation

542 measures for conservation genetics. Evol. Appl., 11(7), 1139-1148.

543 Joubert, E., Joubert, M. E., Bester, C., de Beer, D., \& De Lange, J. H. (2011). Honeybush

544 (Cyclopia spp.): From local cottage industry to global markets: The catalytic and supporting role

545 of research. S. Afr. J. Bot., 77(4), 887-907.

546 Kamvar, Z. N., Tabima, J. F., \& Granwald, N. J. (2014). Poppr: An R package for genetic

547 analysis of populations with clonal, partially clonal, and/or sexual reproduction. PeerJ, 2, e281.

548 Klopfstein, S., Currat, M., \& Excoffier, L. (2006). The fate of mutations surfing on the wave of a

549 range expansion. Mol. Biol. Evol., 23(3), 482-490.

550 Lemmon, A. R., Emme, S. A., \& Lemmon, E. M. (2012). Anchored hybrid enrichment for

551 massively high-throughput phylogenomics. Syst. Biol., 61(5), 727-744.

552 Levin, D. A., Francisco-Ortega, J., \& Jansen, R. K. (1996). Hybridization and the extinction of

553 rare plant species. Conserv. Biol., 10(1), 10-16.

554 Li, F., Niu, B., Huang, Y., \& Meng, Z. (2012). Application of high-resolution DNA melting for

555 genotyping in lepidopteran non-model species: Ostrinia furnacalis (Crambidae). PLoS One,

$5567(1)$, e29664.

557 Li, M., Zhou, L., Palais, R. A., \& Wittwer, C. T. (2014). Genotyping accuracy of high-resolution

558 DNA melting instruments. Clin. Chem., 60(6), 864-872.

559 Liew, M., Pryor, R., Palais, R., Meadows, C., Erali, M., Lyon, E., \& Wittwer, C. (2004).

560 Genotyping of single-nucleotide polymorphisms by high-resolution melting of small amplicons.

561 Clin. Chem., 50(7), 1156-1164.

562 McGregor, G. K. (2017). Industry Review: An overview of the honeybush industry. Retrieved

563 from: Department of Environmental Affairs and Development Planning, Cape Town,

564 https://www.westerncape.gov.za/eadp/files/atoms/files/eadp696_an_overview_of_the_honeybus

565 h_industry_may2017_0.pdf.

566 Motsa, M. M., Bester, C., Slabbert, M. M., Hannweg, K., \& Booyse, M. (2018). Flow cytometry:

567 A quick method to determine ploidy levels in honeybush (Cyclopia spp.). Genet. Resour. Crop

568 Evol., 65(6), 1711-1724.

569 Nei, M. (1973). Analysis of gene diversity in subdivided populations. Proc. Natl. Acad. Sci.,

$57070(12), 3321-3323$. 
571 Niemandt, M., Roodt-Wilding, R., Tobutt, K. R., \& Bester, C. (2018). Microsatellite marker

572 applications in Cyclopia (Fabaceae) species. S. Afr. J. Bot., 116, 52-60.

573 Nunziata, A., De Benedetti, L., Marchioni, I., \& Cervelli, C. (2019). High throughput measure of

574 diversity in cytoplasmic and nuclear traits for unraveling geographic distribution of rosemary.

575 Ecol. Evol., 9(7), 3728-3739.

576 Potts, A. J. (2017). Genetic risk and the transition to cultivation in Cape endemic crops: The

577 example of honeybush (Cyclopia)? S. Afr. J. Bot., 110, 52-56.

578 Prevosti, A., Ocana, J., Alonso, G., Ocaa, J., \& Alonso, G. (1975). Distances between

579 populations of Drosophila subobscura, based on chromosome arrangement frequencies. Theor.

580 Appl. Genet., 45(6), 231-241.

581 QGIS Development Team (2018). QGIS Geographic Information System. Open Source

582 Geospatial Foundation Project. http://qgis.osgeo.org

583 Radvansky, J., Bazsalovicsova, E., Kralova-Hromadova, I., Minarik, G., \& Kadasi, L. (2011).

584 Development of high-resolution melting (HRM) analysis for population studies of Fascioloides

585 magna (Trematoda, Fasciolidae), the giant liver fluke of ruminants. Parasitol. Res., 108(1), 201-

586209.

587 R Core Team. R: a language and environment for statistical computing. (2018).

588 Reed, G. H., \& Wittwer, C. T. (2004). Sensitivity and specificity of single-nucleotide

589 polymorphism scanning by high-resolution melting analysis. Clin. Chem., 50(10), 1748-1754.

590 Rousset, F. (1997). Genetic differentiation and estimation of gene flow from F-statistics under

591 isolation by distance. Genetics, 145(4), 1219-1228.

592 SANBI. (2019). Threatened Species Programme: SANBI Red List of South African Plants.

593 Retrieved from: http://redlist.sanbi.org/index.php.

594 Sanger, F., Nicklen, S., \& Coulson, A. R. (1977). DNA sequencing with chain-terminating

595 inhibitors. Proc. Natl. Acad. Sci. U. S. A., 74(12), 5463-5467.

596 Schaal, B. A., Hayworth, D. A., Olsen, K. M., Rauscher, J. T., \& Smith, W. A. (1998).

597 Phylogeographic studies in plants: Problems and prospects. Mol. Ecol., 7(4), 465-474.

598 Schaal, B. A., Hayworth, D. A., Olsen, K. M., Rauscher, J. T., \& Smith, W. A. (1998).

599 Phylogeographic studies in plants: Problems and prospects. Mol. Ecol., 7(4), 465-474.

600 Schutte, A. L. (1997). Systematics of the genus Cyclopia Vent. (Fabaceae, Podalyrieae).

601 Edinburgh J. Bot., 54(2), 125-170.

602 Shaw, J., Lickey, E. B., Beck, J. T., Farmer, S. B., Liu, W., Miller, J., \& Small, R. L. (2005). The

603 tortoise and the hare II: Relative utility of 21 noncoding chloroplast DNA sequences for

604 phylogenetic analysis. Am. J. Bot., 92(1), 142-166.

605 Shaw, J., Lickey, E. B., Schilling, E. E., \& Small, R. L. (2007). Comparison of whole chloroplast

606 genome sequences to choose noncoding regions for phylogenetic studies in angiosperms: The

607 tortoise and the hare III. Am. J. Bot., 94(3), 275-288.

608 Sillo, F., Giordano, L., Zampieri, E., Lione, G., De Cesare, S., \& Gonthier, P. (2017). HRM

609 analysis provides insights on the reproduction mode and the population structure of

610 Gnomoniopsis castaneae in Europe. Plant Pathol., 66(2), 293-303.

611 Simko, I. (2016). High-resolution DNA melting analysis in plant research. Trends Plant Sci.,

612 21(6), 528-537.

613 Slatkin, M. (1993). Isolation by distance in equilibrium and non-equilibrium populations.

614 Evolution, 47(1), 264-279. 
615 Smith, B. L., Lu, C. P., \& Alvarado Bremer, J. R. (2010). High-resolution melting analysis

616 (HRMA): a highly sensitive inexpensive genotyping alternative for population studies. Mol. Ecol.

617 Resour., 10(1), 193-196.

618 Taylor, S., Scott, R., Kurtz, R., Fisher, C., Patel, V., \& Bizouarn, F. (2011). A practical guide to

619 high resolution melt analysis genotyping. Retrieved from: http://www.bio-

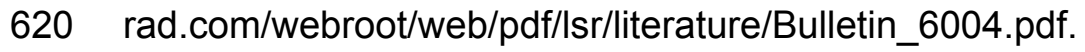

621 Thompson, J. D., Higgins, D. G., \& Gibson, T. J. (1994). CLUSTAL W: Improving the sensitivity 622 of progressive multiple sequence alignment through sequence weighting, position-specific gap 623 penalties and weight matrix choice. Nucleic Acids Res., 22(22), 4673-4680.

624 Tindall, E. A., Petersen, D. C., Woodbridge, P., Schipany, K., \& Hayes, V. M. (2009). Assessing 625 high-resolution melt curve analysis for accurate detection of gene variants in complex DNA 626 fragments. Hum. Mutat., 30(6), 876-883.

627 Van Der Bank, M., Chase, M.W., Van Wyk, B. E., Fay, M. F., Van Der Bank, F. H., Reeves, G. 628 \& Hulme, A. (2002), Systematics of the tribe Podalyrieae (Fabaceae) based on DNA, 629 morphological and chemical data. Bot. J, 139, 159-170.

630 Vossen, R. H., Aten, E., Roos, A., \& den Dunnen, J. T. (2009). High-resolution melting analysis 631 (HRMA): More than just sequence variant screening. Hum. Mutat., 30(6), 860-866.

632 Wright, S. (1943). Isolation by distance. Genetics, 28(2), 114-138.

633 Yamagata, Y., Yoshimura, A., Anai, T., \& Watanabe, S. (2018). Selection criteria for 634 SNP loci to maximize robustness of high-resolution melting analysis for plant breeding. 635 Breed. Sci., 68(4), 488-498. 


\section{Figure 1}

Sample distribution map

Study domain superimposed with the distribution of the CFRs fynbos biome, to which Cyclopia is endemic. Inset indicates the position of the study domain in relation to South Africa and the African continent. Distribution of samples included in non-coding cpDNA haplotype screening for HRM primer development are displayed (filled circles) in conjunction with the locations of the $C$. subternata populations included in the phylogeographic analysis (open circles). Closed circles are numbered based on species identity: $1=C$. galioides, $2=C$. genistoides, $3=$ C. buxifolia, $4=C$. maculata, $5=$ C. sessilifolia, $6=C$. burtonii, $7=C$. aurescens, $8=$ C. bolusii, $9=$ C. subternata, $10=$ C. plicata, $11=$ C. alpina, $12=C$. intermedia, $13=$ C. longifolia, $14=$ C. pubescens .

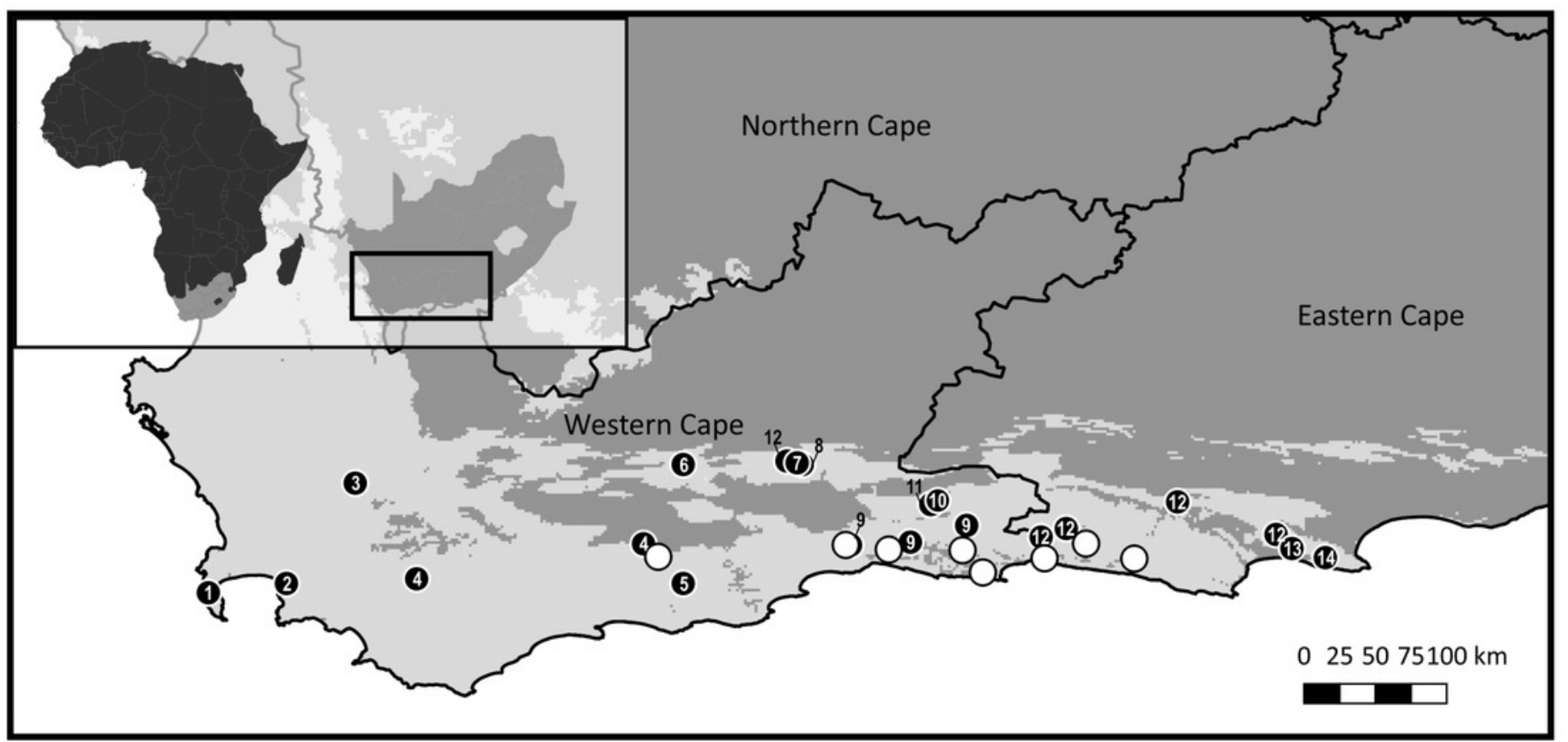




\section{Figure 2}

High Resolution Melt curve examples

Melt curves and their difference curves for the PCR products amplified by three of the genus specific primers developed. Curves are ordered in decreasing HRM clustering accuracy and the bottom curves (E,F) were generated using the primer pair MLT T1-MLT T2 (TrnQ-5'rps16 intergenic spacer) that was excluded from HRM analysis due to poor amplification resulting in inconsistent melt curve production, the details of this primer pair, in addition to all primer pairs that were excluded from HRM haplotype discrimination analysis due to poor PCR amplification, are provided in Table S1. HRM curves (A,C,E), the normalized change in florescence associated with PCR product dissociation when heated. Melt domain identification and melt curve normalization was automated by the HRM software in this study, this process may be required to be performed manually on other platforms. A reference melt curve is selected and used as a baseline to plot melt curve differences across the melt domain, therefore difference curves $(B, D, E)$ have different $X$ axes. HRM clusters are automatically generated and colorised by the HRM software used. Melt curves were generated from the PCR products generated using the primer pairs, $(A, B)$ MLT S1 - MLT S2 (atpl-atpH intergenic spacer), (C,D) MLT C3 - MLT C4 (trnG-trnG2G intergenic spacer), and (E,F) MLT T1 - MLT T2 (trnQ-5'rps16 intergenic spacer). 

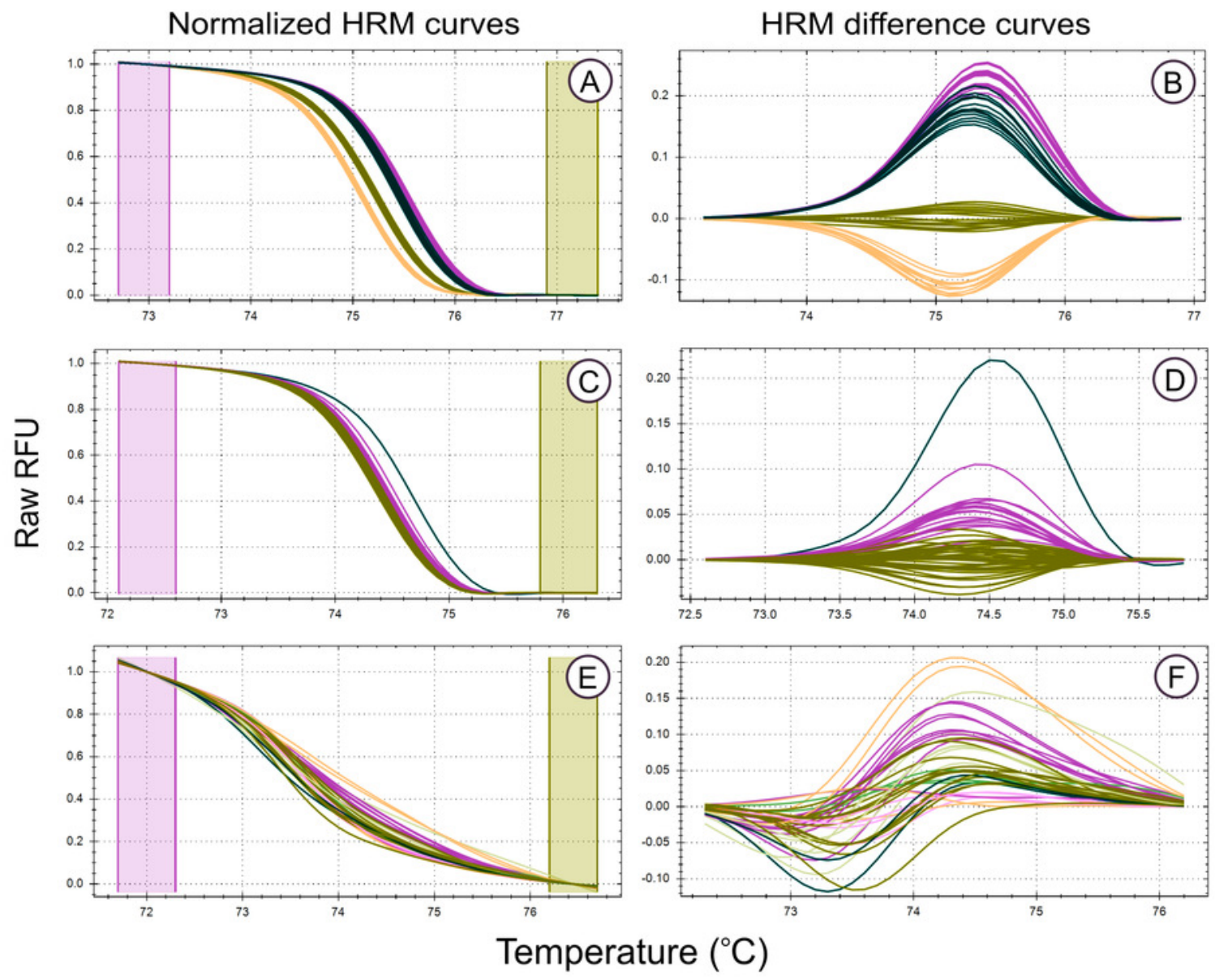
Figure 3

Framework used to developed, test, and apply HRM to the genus Cyclopia, a group of non-model organisms.

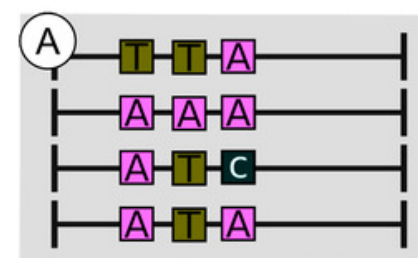

Step 1: Identify polymorphic sites from sequence data.

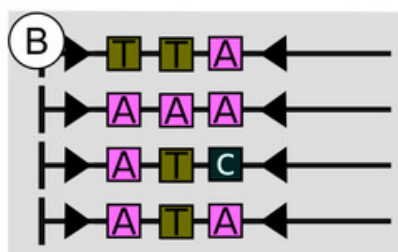

Step 2: Design primers that flank polymorphic sites.

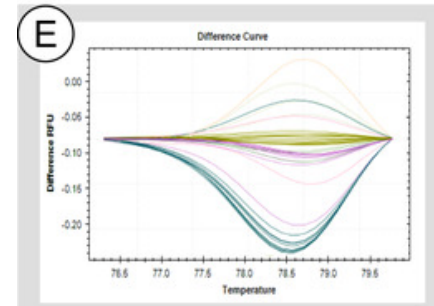

Step 5: Apply the top performing primer pairs, with the highest specificity and accuracy, to detect genetic variation in non-model organisims. Sequence only a sub set of individuals assigned to a HRM cluster for haplotype confirmation.

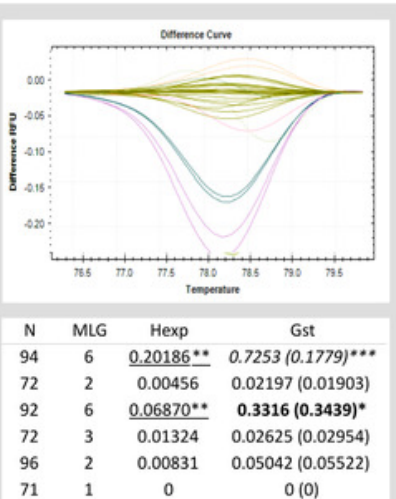

0 (0)

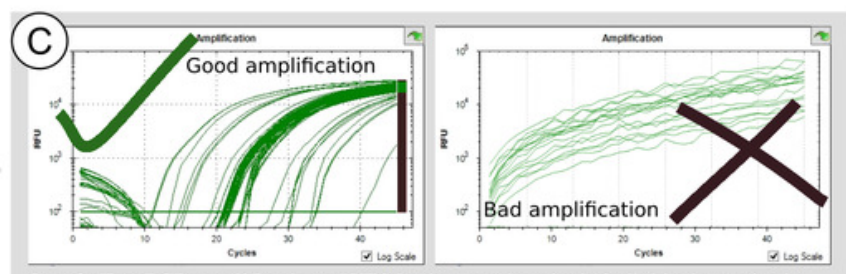

Step 3: Test PCR amplification of HRM primers using single individual samples in replicate per haplotype. Post amplification HRM curve generation is performed on all PCR-ed asseccions, but primers consitantly failing to amplify PCR products are excluded from HRM analysis. Samples that amplified but failed to meet the PCR quality requirments occur within the red bar to the right of the amplification curve,

only samples in the green were used to test HRM haplotype discrimination.
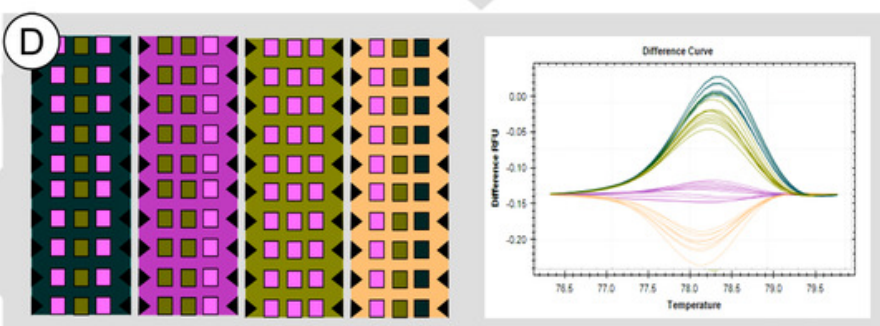

Step 4: Test HRM clustering of sequenced haplotypes using data generated in Step 3 above, only primers that produced consistant amplification curves are included in HRM analysis. Sensitivity, specificity and accuracy was calculated for each primer pair that produced good quality PCR amplification curves. 
Figure 4

Summary of the (A) specificity, (B) sensitivity and (C) accuracy for the regions used to test haplotype discrimination by HRM. 


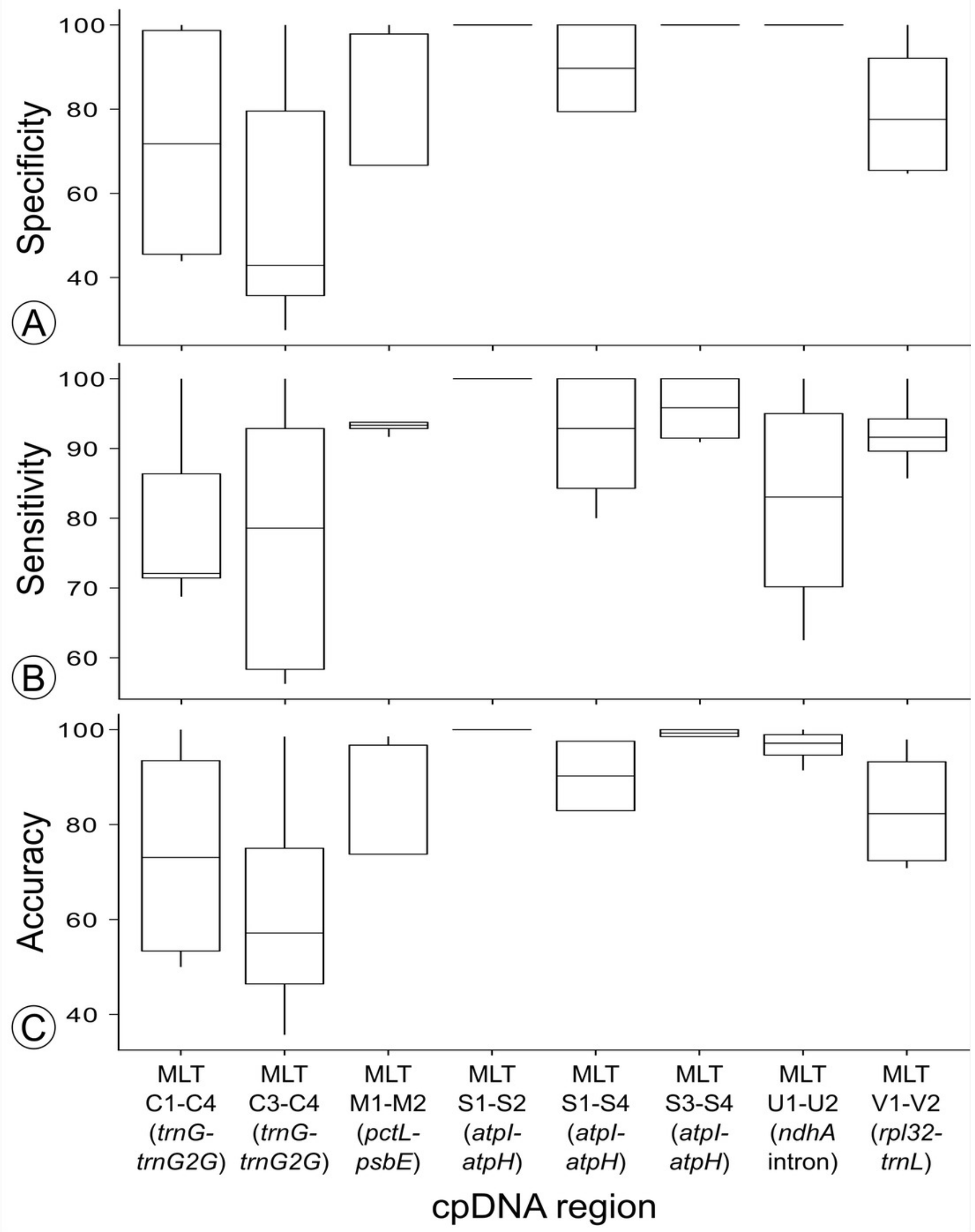




\section{Figure 5}

Haplotype distribution and number of accessions for the eight $C$. subternata populations screened via HRM.

Black circles mark $C$. intermedia samples collected from the Swartberg mountains and included as out-group taxa. Inset is the genealogical relationship between haplotypes ascertained using the Statistical Parsimony algorithm. Haplotype frequency is indicated as a proportion of the circles representing each population, with total number of accessions provided in parenthesis. The color-coding in the map corresponds to the SP network. Population naming follows the description in Table 4. GAR = Garcia's Pass located in the Langeberg, OUT = Outeniqua Pass and BP =Bergplaas MTO located in the western Outeniqua mountains, KNYS = Diepwalle Knysna and PLETT = Plettenberg Bay in the eastern Outeniqua mountains, and the BKB = Bloukrans Bridge, $\mathrm{LK}=$ Langkloof, and $\mathrm{KP}=$ Kareedouw Pass in the Tsitsikamma mountains.

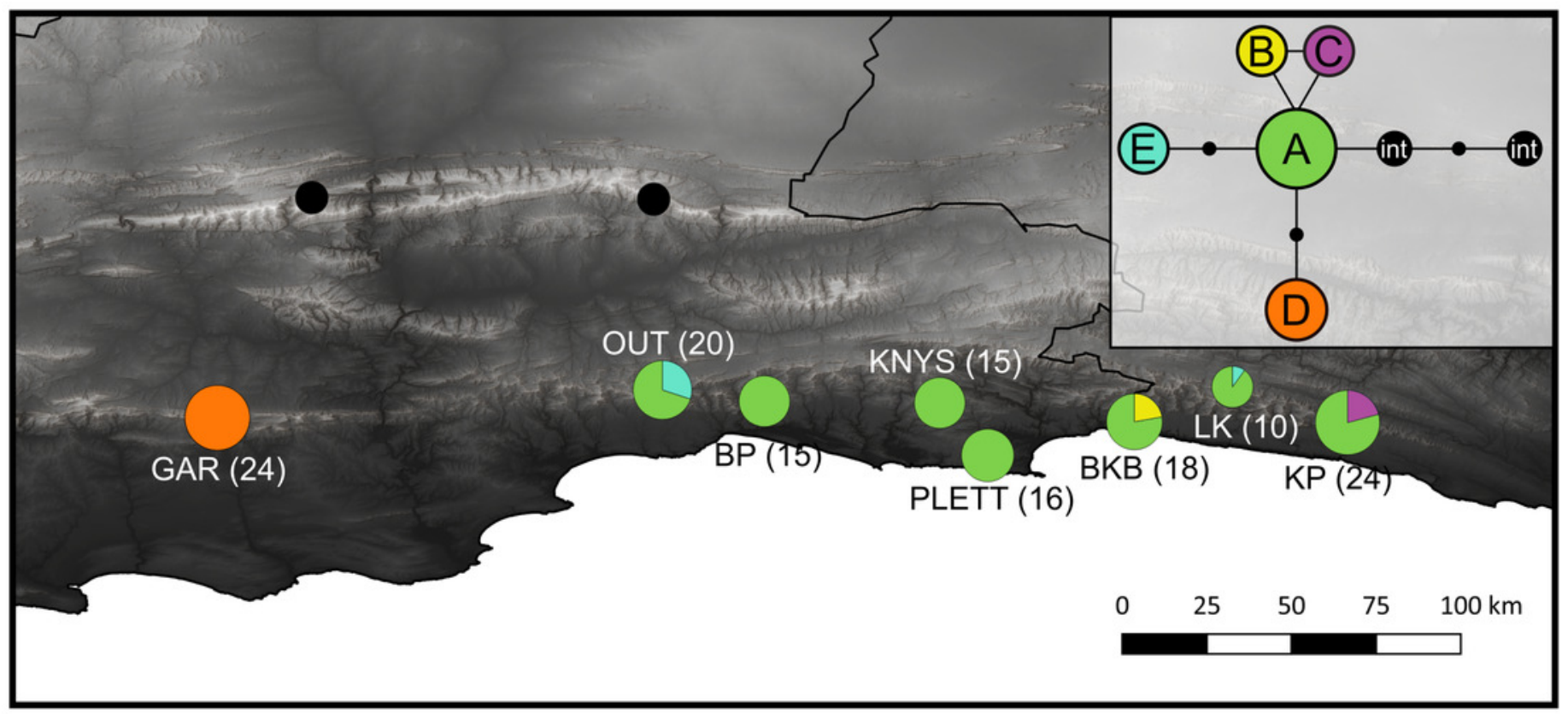




\section{Table $\mathbf{1}$ (on next page)}

Species and non-coding cPDNA regions screened for HRM primer development for the non-model plant genus Cyclopia Vent. 


\begin{tabular}{|c|c|c|c|c|c|c|c|c|c|c|c|c|}
\hline Species & $\begin{array}{c}\text { rp/32-trnL } \\
\text { intergenic } \\
\text { spacer }\end{array}$ & $\begin{array}{l}n d h A \\
\text { intron }\end{array}$ & $\begin{array}{l}\text { Non-codi } \\
\text { trnQ- } \\
50 r p s 16 \\
\text { intergenic } \\
\text { spacer }\end{array}$ & $\begin{array}{c}\text { ding } \mathrm{cpDN} / \\
\text { atpl-atpH } \\
\text { intergenic } \\
\text { spacer }\end{array}$ & $\begin{array}{l}\text { A regions s } \\
\text { petL- } \\
p s b E \\
\text { intergenic } \\
\text { spacer }\end{array}$ & $\begin{array}{c}\text { equenced } \\
\text { trnD- } \\
p s b M \\
\text { intergeni } \\
\text { c spacer }\end{array}$ & $\begin{array}{l}\text { (dependen } \\
\text { trnG- } \\
\text { trnG2G } \\
\text { intergenic } \\
\text { spacer }\end{array}$ & $\begin{array}{c}\text { It on succes } \\
\text { 30trnV- } \\
\text { ndhC } \\
\text { intergenic } \\
\text { spacer }\end{array}$ & $\begin{array}{c}\text { TrnfM- } \\
\text { trnS }\end{array}$ & $\begin{array}{c}\text { psbJ- } \\
\text { petA }\end{array}$ & $\begin{array}{l}\text { psal- } \\
\text { accD }\end{array}$ & $\begin{array}{c}\text { psbD- } \\
\text { trnT }\end{array}$ \\
\hline C. alpina & & $\mathbf{x}$ & & & & & & $x$ & $\mathbf{x}$ & $x$ & & \\
\hline C. aurescens & & $x$ & & $x$ & & & & $x$ & $x$ & $x$ & $x$ & $x$ \\
\hline C. bolusii & & $x$ & & & & & & & & & & \\
\hline C. burtonii & & & $\mathbf{x}$ & $\mathbf{x}$ & & & $x$ & $x$ & & & & \\
\hline C. buxifolia & & $x$ & & $x$ & $x$ & & $\mathbf{x}$ & & & & & \\
\hline C. galioides & & & & $\mathbf{x}$ & & & & & & & & \\
\hline C. genistoides & & $x$ & & $x$ & & & $\mathbf{x}$ & & & $x$ & & $x$ \\
\hline C. intermedia & $x$ & $x$ & $x$ & $x$ & & $x$ & $x$ & $\mathbf{x}$ & $x$ & $x$ & $x$ & $x$ \\
\hline C. longifolia & $x$ & & $x$ & $x$ & $x$ & $x$ & $x$ & $x$ & $x$ & $x$ & $x$ & $x$ \\
\hline C. maculata & & $x$ & & & & & & $x$ & & $x$ & $x$ & $x$ \\
\hline C. plicata & $\mathbf{x}$ & $x$ & & & & & & $x$ & $\mathbf{x}$ & $x$ & $x$ & \\
\hline C. pubescens & $x$ & $x$ & $x$ & $x$ & $x$ & $x$ & $x$ & $x$ & $\mathbf{x}$ & $x$ & $x$ & \\
\hline C. sessilifolia & $x$ & $x$ & & $\mathbf{x}$ & $x$ & $x$ & $x$ & & $x$ & $x$ & $x$ & \\
\hline C. subternata & $\mathbf{x}$ & $\mathbf{x}$ & & $\mathbf{x}$ & $\mathbf{x}$ & $\mathbf{x}$ & $\mathbf{x}$ & & $\mathbf{x}$ & $\mathbf{x}$ & $\mathbf{x}$ & $\mathbf{x}$ \\
\hline
\end{tabular}

Following PCR amplification, only clear, bright bands visualized through gel electrophoresis were selected for sequencing with a maximum of six and a minimum of one sample selected for sequencing per species. 


\section{Table 2 (on next page)}

Cyclopia specific primers designed for testing HRM haplotype discrimination

Primers used to screen haplotype variation in wild $C$. subternata populations are indicated in bold. Primer details provided include; non-coding cpDNA region the primers are located in, as well as each primers' annealing temperature (Tm) in degrees Celcius, GC content, and sequence motif. 


\begin{tabular}{clcccc}
\hline Region & Primer & Direction & $\mathrm{Tm}\left({ }^{\circ} \mathrm{C}\right)$ & $\mathrm{GC}(\%)$ & Sequence $\left(5^{\prime} \rightarrow 3^{\prime}\right)$ \\
\hline \multirow{3}{*}{ trnG intron } & MLT_C1 & $\mathrm{F}$ & 57.3 & 43.5 & ACTCCTCTTCTATTCATGGGGA \\
& MLT_C2 & $\mathrm{R}$ & 58.0 & 50.0 & \\
& MLT_C3 & $\mathrm{F}$ & 61.8 & 40.9 & TCAACGAACGATTCGAGGAATA \\
& MLT_C4 & $\mathrm{R}$ & 61.1 & 45.5 & TGCTTCAATCTCTCCTACCCAA \\
\hline \multirow{2}{*}{ pctL-psbE } & MLT_M1 & $\mathrm{F}$ & 58.0 & 43.5 & TGTCGAGAACCCTTATACTCTCA \\
intergenic spacer & MLT_M2 & $\mathrm{R}$ & 58.7 & 47.6 & TACCAAGGGTGTCTTTCGAGT \\
\hline \multirow{2}{*}{ atpl-atpH } & MLT_S1 & $\mathbf{F}$ & 64.3 & 50 & ATTACAGATGAAACGGAAGGGC \\
intergenic spacer & MLT_S2 & $\mathbf{R}$ & 61.5 & 45.5 & TGGGGGTTTCAAAGCAAAGG \\
& MLT_S3 & $\mathbf{F}$ & 61.5 & 45.5 & CCTTTGCTTTGAAACCCCCA \\
& MLT_S4 & $\mathbf{R}$ & 66.4 & 36.5 & TTCCCGTTTCATTCATTCACATTCA \\
\hline \multirow{2}{*}{ ndhA intron } & MLT_U1 & $\mathbf{F}$ & 59.1 & 40.0 & AGGTACTTCTGAATTGATCTCATCC \\
& MLT_U2 & $\mathbf{R}$ & 62.2 & 52.4 & GCAGTACTCCCCACAATTCCA \\
\hline in/32-trnL & MLT_V1 & $\mathrm{F}$ & 59.9 & 60.0 & CTCCTTCCCTAAGAGCAGCG \\
intergenic spacer & MLT_V2 & $\mathrm{R}$ & 59.2 & 40.0 & GTTGGAATAATCTGAATTAGCCGGA \\
\hline
\end{tabular}




\section{Table 3 (on next page)}

Nucleotide differences and clustering results for HRM discrimination of known haplotype

Sample ID of the accessions that were PCR amplified in replicates of 16 , the number of replicates that successfully amplified during PCR and subject to HRM analysis is given (N), followed by HRM haplotype discrimination (sensitivity, specificity and accuracy), the grouping of each replicate into a HRM cluster is provided for each haplotype amplified per primer combination (clusters 1 - 11), a summary of the nucleotide differences between haplotypes is also provided. 


\begin{tabular}{llllllllllllll}
\hline Primer pair & $N$ & Sen Spe Acc & HRM grouping of replicates into cluster 1- \\
cluster 11 & Nucleotide difference summary
\end{tabular}

\begin{tabular}{|c|c|c|c|c|c|c|c|c|c|c|c|c|}
\hline \multirow[t]{2}{*}{$\begin{array}{c}\text { MLT C1-MLT C4 (15 } \\
\text { (TrnG intron) }\end{array}$} & & & & & & & & & 192 & 20 & \multicolumn{2}{|c|}{$72 \quad 205$} \\
\hline & & & & & & & & & $\mathrm{T}$ & A & $\mathrm{T}$ & A \\
\hline Haplotype A & 14 & 71 & 94 & 88 & 2 & 10 & & & G & $\mathrm{T}$ & G & . \\
\hline Haplotype B & 16 & 69 & 44 & 52 & 11 & & 4 & 1 & . & . & . & . \\
\hline Haplotype C & 11 & 91 & 49 & 58 & 10 & 1 & & & . & . & . & C \\
\hline Haplotype D & 11 & 73 & 44 & 50 & 8 & 1 & 3 & & . & . & G & \\
\hline
\end{tabular}

MLT C3-MLT C4 (236 bp)

(TrnG intron)

Haplotype B

Haplotype C

Haplotype D $\begin{array}{lllll}14 & 100 & 43 & 57 & 14\end{array}$

$\begin{array}{lllllll}16 & 56 & 27 & 36 & 9 & 6 & 1\end{array}$

$\begin{array}{lllllll}12 & 58 & 79 & 75 & 4 & 7 & 1\end{array}$

$\begin{array}{llllll}4 & 79 & 36 & 46 & 11 & 3\end{array}$

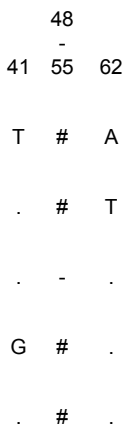

\# = AAAAATTG

MLT M1-MLT M2 (170 bp)
(pctL-psbE intergenic

spacer)

$\begin{array}{llll}84 & 88 & 110 & 118\end{array}$

G $\quad G \quad G \quad A$

Haplotype A

$\begin{array}{llll}15 & 93 & 98 & 97\end{array}$

14

Haplotype B

$\begin{array}{lllll}16 & 94 & 67 & 74 & 15\end{array}$

Haplotype C

14

$98 \quad 97$

113

Haplotype D

16

$\begin{array}{llll}94 & 67 & 74 & 15\end{array}$

1

A.

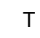

T $\quad G$
MLT S1-MLT S2 (217 bp)

(atpl-atpH intergenic

spacer) $\begin{array}{llll}53 & 54 & 62- & 80\end{array}$ 
$\begin{array}{llllll}\text { Haplotype A } & 12 & 100 & 100 & 100 & 12\end{array}$

$\begin{array}{llllll}\text { Haplotype B } & 15 & 100 & 100 & 100 & 15\end{array}$

$\begin{array}{llllll}\text { Haplotype C } & 11 & 100 & 100 & 100 & 11\end{array}$

$\begin{array}{llllll}\text { Haplotype D } & 14 & 100 & 100 & 100 & 14\end{array}$

. $\quad-A$

A C -

A C \#

\# = TTCATAGATAACTAGTTAG
MLT S1-MLT S4 (527 bp)
(atpl-atpH intergenic

spacer)

Haplotype A

$\begin{array}{lllll}14 & 100 & 79 & 83 & 14\end{array}$

Haplotype B

$\begin{array}{llll}10 & 80 & 100 & 98\end{array}$

Haplotype C

$\begin{array}{lllll}14 & 100 & 79 & 83 & 14\end{array}$

Haplotype D

Haplotype E

$\begin{array}{llll}14 & 86 & 100 & 98\end{array}$

$\begin{array}{lllll}16 & 100 & 100 & 100 & 16\end{array}$

Haplotype F

$14 \quad 71 \quad 100 \quad 95$

10

82

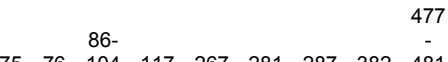

$\begin{array}{lllllllll}75 & 76 & 104 & 117 & 267 & 281 & 287 & 382 & 481\end{array}$

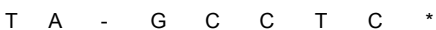

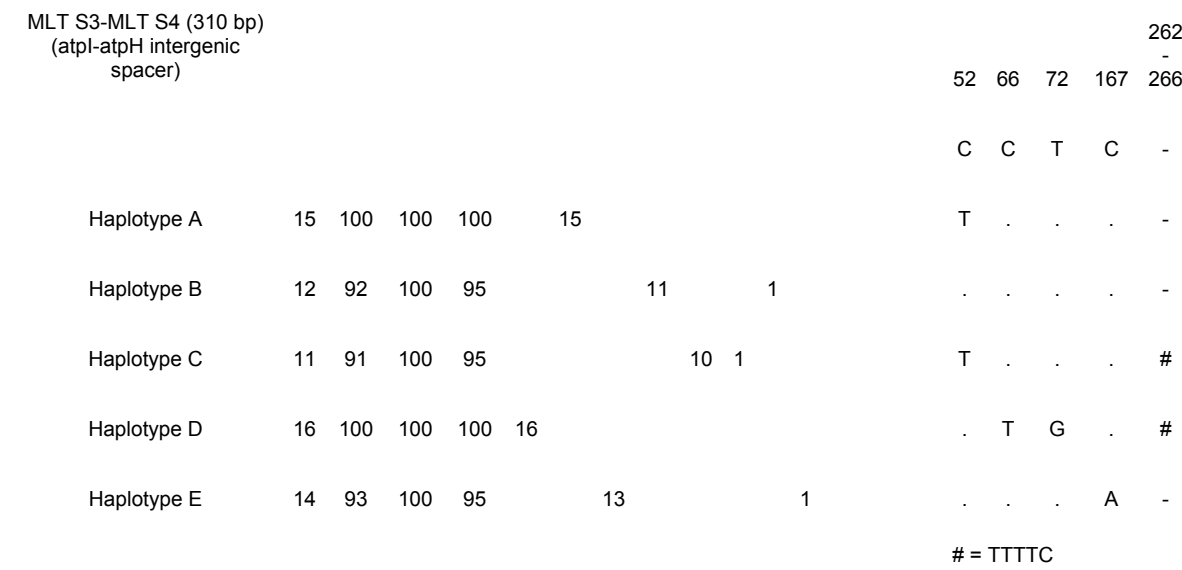

MLT U1-MLT U2 (345 bp)

(ndhA intron)

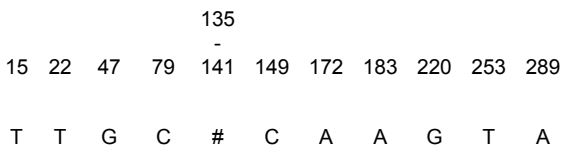

Haplotype A

$\begin{array}{lllll}16 & 100 & 100 & 100 & 16\end{array}$

Haplotype B

$\begin{array}{llll}11 & 73 & 100 & 96\end{array}$

8

3

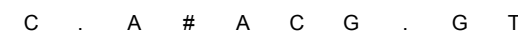




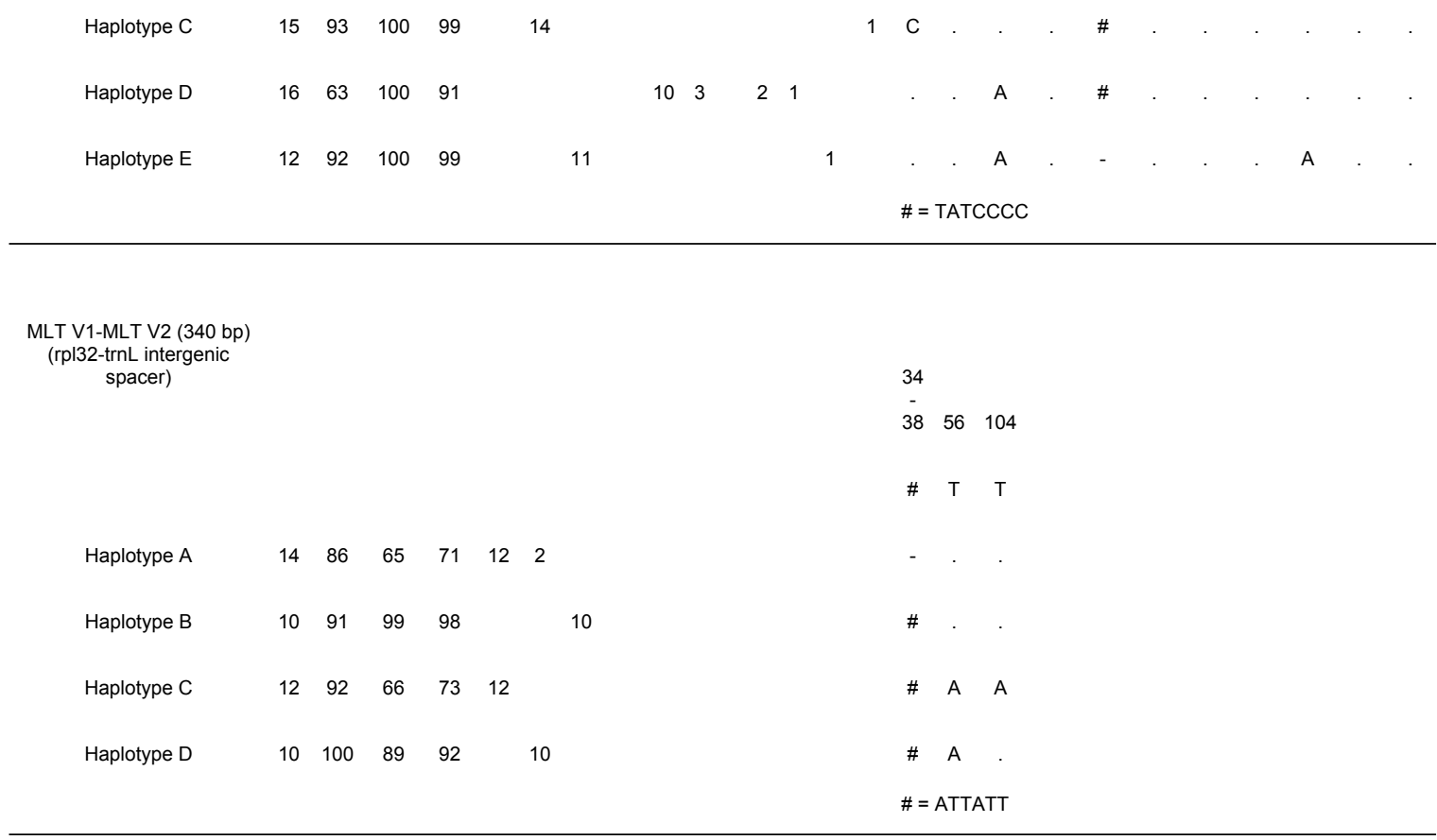




\section{Table 4 (on next page)}

Protocol for PCR amplification and subsequent HRM curve generation. Primer specific annealing temperatures (Tm) are provided in Table 2 . 


\begin{tabular}{|ccccc|}
\hline Process & Step & Temperature & Time & Number of Cycles \\
\hline & Initial Denaturing & $95^{\circ} \mathrm{C}$ & $2 \mathrm{~min}$ & 1 \\
PCR Amplification & Denaturing & $95^{\circ} \mathrm{C}$ & $10 \mathrm{sec}$ \\
& Annealing/Extension + Plate Read & Primers mean Tm & $30 \mathrm{sec}$ & 40 \\
& Extension + Plate Read & $72^{\circ} \mathrm{C}$ & $30 \mathrm{sec}$ & 1 \\
& Heteroduplex Formation & $95^{\circ} \mathrm{C}$ & $30 \mathrm{sec}$ & 1 \\
HRM Analysis & & $60^{\circ} \mathrm{C}$ & $1 \mathrm{~min}$ & 1 \\
& HRM + Plate Read & $65-95^{\circ} \mathrm{C}$ & $10 \mathrm{sec} / \mathrm{step}$ & 1 \\
\hline
\end{tabular}




\section{Table 5 (on next page)}

Cyclopia subternata population locations

The geographic co-ordinates, number of accessions screened via HRM, and haplpotype frequencies (as detected by HRM and verified by sequencing) are given for each $C$. subternata population. Nucleotide differences among haplotypes are provided in Table S3. 


\begin{tabular}{|c|c|c|c|c|c|c|c|c|c|}
\hline \multirow[t]{2}{*}{ Mountain range } & \multirow[t]{2}{*}{ Population } & \multicolumn{2}{|c|}{ Co-ordinates } & \multirow[t]{2}{*}{$\mathrm{N}$} & \multicolumn{5}{|c|}{ Haplotype } \\
\hline & & $S$ & $\mathrm{E}$ & & A & $\mathrm{B}$ & C & $\mathrm{D}$ & $E$ \\
\hline \multirow{3}{*}{$\begin{array}{l}\text { Langeberg } \\
\text { Outeniqua W }\end{array}$} & Garcia's pass (GAR) & -33.96 & 21.22 & 24 & - & - & - & 24 & - \\
\hline & Outeniqua Pass (OUT) & -33.88 & 22.40 & 20 & 14 & - & - & - & 6 \\
\hline & Bergplaas MTO (BP) & -33.91 & 22.67 & 15 & 15 & - & - & - & - \\
\hline \multirow[t]{2}{*}{ Outeniqua E } & Diepwalle, Knysna (KNYS) & -33.92 & 23.14 & 15 & 15 & - & - & - & - \\
\hline & Plettenberg bay (PLETT) & -34.06 & 23.26 & 16 & 16 & - & - & - & - \\
\hline \multirow[t]{3}{*}{ Tsitsikamma } & Bloukrans Bridge (BKB) & -33.97 & 23.65 & 18 & 14 & - & 4 & - & - \\
\hline & Langkloof (LK) & -33.87 & 23.91 & 10 & 9 & - & - & - & 1 \\
\hline & Kareedouw pass (KP) & -33.97 & 24.22 & 24 & 19 & 5 & - & - & - \\
\hline
\end{tabular}

10

11 
Table 6(on next page)

Nucleotide varition not differentiated by HRM 


\begin{tabular}{|c|c|c|c|}
\hline Primers & Haplotypes & Nucleotide difference & Specificity \\
\hline \multirow{6}{*}{$\begin{array}{l}\text { MLT C1 - MLT C4 } \\
\text { (TrnG intron) }\end{array}$} & C-D & $\mathrm{T} \leftrightarrow \mathrm{G} \& \mathrm{C} \leftrightarrow \mathrm{A}$ & 18 \\
\hline & $B-C$ & $A \leftrightarrow C$ & 20 \\
\hline & $B-D$ & $\mathrm{~T} \leftrightarrow \mathrm{G}$ & 29 \\
\hline & $A-C$ & $\mathrm{GT} \leftrightarrow \mathrm{TA}, \mathrm{G} \leftrightarrow \mathrm{T} \& \mathrm{~T} \leftrightarrow \mathrm{A}$ & 88 \\
\hline & $A-D$ & $G \leftrightarrow T \& T \leftrightarrow A$ & 88 \\
\hline & $A-B$ & $\mathrm{GT} \leftrightarrow \mathrm{TA} \& \mathrm{G} \leftrightarrow \mathrm{T}$ & 93 \\
\hline \multirow{6}{*}{$\begin{array}{l}\text { MLT C3 - MLT C4 } \\
\text { (TrnG intron) }\end{array}$} & $A-D$ & $\mathrm{~T} \leftrightarrow \mathrm{A}$ & 11 \\
\hline & $A-B$ & $8 \mathrm{bp}$ indel $\& \mathrm{~T} \leftrightarrow \mathrm{A}$ & 22 \\
\hline & B-D & $8 \mathrm{bp}$ indel & 33 \\
\hline & $B-C$ & $\mathrm{~T} \leftrightarrow \mathrm{G} \& 8 \mathrm{bp}$ indel & 65 \\
\hline & C-D & $\mathrm{G} \leftrightarrow \mathrm{T}$ & 73 \\
\hline & $\mathrm{A}-\mathrm{C}$ & $T \leftrightarrow G \& T \leftrightarrow A$ & 83 \\
\hline \multirow{2}{*}{$\begin{array}{c}\text { MLT M1 - MLT M2 } \\
\text { (pctL-psbE intergenic spacer) }\end{array}$} & $A-C$ & $G \leftrightarrow T \& A \leftrightarrow G$ & 6 \\
\hline & B-D & $A \leftrightarrow G \& G \leftrightarrow T$ & 93 \\
\hline $\begin{array}{c}\text { MLT S1 - MLT S4 } \\
\text { (atpl-atpH intergenic spacer) }\end{array}$ & $A-C$ & 5 bp indel & 0 \\
\hline \multirow{3}{*}{$\begin{array}{c}\text { MLT V1 - MLT V2 } \\
\text { (rpl32-trnL intergenic spacer) }\end{array}$} & $\mathrm{A}-\mathrm{C}$ & $6 \mathrm{bp}$ indel, $T \leftrightarrow \mathrm{A} \& \mathrm{~T} \leftrightarrow \mathrm{A}$ & 11 \\
\hline & $A-D$ & $6 \mathrm{bp}$ indel $\& \mathrm{~T} \leftrightarrow \mathrm{A}$ & 93 \\
\hline & C-D & $\mathrm{A} \leftrightarrow \mathrm{T}$ & 96 \\
\hline
\end{tabular}

